\title{
Degree Based Topological Indices of n-Butane Isomers
}

\author{
Mallikarjun Hottinavar ${ }^{1}$, Snehal Thabaj ${ }^{2}$ \\ ${ }^{1}$ Department of Mathematics, SSS Govt. First Grade College, Mudalgi-591312, Karnataka, India \\ ${ }^{2}$ Departments of Mathematics, HSIT Nidasoshi- 591236, Karnataka, India
}

\begin{abstract}
Let $G$ be a molecular graph. A graph $G=(V(G), E(G))$ consists of the vertex set $V(G)$ and the edge set $E(G)$ such that each edge $e$ in $E$ is assigned an unordered pair of vertices $(u, v)$, called the end vertices of $e$. The skeleton of an organic molecule (usually, of a hydrocarbon) represents simple graph. Thus the vertices of molecular graph represent the carbon atoms, and edges the carbon-carbon bonds. In molecular graph we have many topological indices. In this paper, we are computing some topological indices values of butane isomers.

Keywords: Graph, Molecular graph, Topological indices.
\end{abstract}

\section{Introduction}

A graph $\mathrm{G}$ Consists Of a finite non-empty set $\mathrm{V}=\mathrm{V}(\mathrm{G})$ of $\mathrm{n}$ vertices together with a prescribed set $\mathrm{E}=\mathrm{E}$ (G) of $m$ unordered pairs of distinct vertices of V. Each of these pairs of vertices is called an edge of G. We consider graphs in which there is no direction for the edges, hence undirected, the graphs which do not contain edges joining the same vertex, i.e. not containing loop, graphs in which not more than one edge joins two vertices so, we consider undirected graphs without multiple edges and loops.

Let $\mathrm{G}$ be a graph and $\mathrm{v} \in \mathrm{V}$. The number of edges incident at $\mathrm{v}$ in $\mathrm{G}$ called the degree (or valences) of the vertex $v$ in $G$ and is denoted by $d_{G}(V)$, or simply $d(v)$ when $G$ requires no explicit reference. A loop at $v$ is to be counted twice in computing the degree of $\mathrm{v}$.

A graph $\mathrm{G}$ with a vertex set $\mathrm{V}(\mathrm{G})=\left(\mathrm{v}_{1}, \mathrm{v}_{2}, \ldots \ldots \ldots \mathrm{v}_{\mathrm{n}}\right)$ and edge set $\mathrm{E}(\mathrm{G})=\left(\mathrm{e}_{1}, \mathrm{e}_{2}, \ldots \ldots \ldots . \mathrm{e}_{\mathrm{n}}\right)$ can also described by means of matrices called adjacency matrices, $A(G)=($ aij $)$ given by

$$
\mathrm{Aij}=\left\{\begin{array}{l}
1 \text { if } v i v j \in E(G) \\
0 \text { if } v i v j \notin E(G) \text { or } i=j
\end{array}\right.
$$

A molecular graph $\mathrm{G}=(\mathrm{V}, \mathrm{E})$ is a simple graph having $\mathrm{n}=|\mathrm{V}|$ nodes and $\mathrm{m}=|\mathrm{E}|$ edges. The nodes $\mathrm{v}_{\mathrm{i}} \in \mathrm{V}$ represent non-hydrogen atoms and the edges $\left(v_{i}, v_{j}\right) \in E$ represent covalent bonds between the corresponding atoms. In particular, hydrocarbons are formed only by carbon and hydrogen atom and their molecular graphs represent the carbon skeleton of the molecule.

Randi $\square$ or Connectivity Index:

\section{Some Degree-Based Topological Indices}

Historically, the first vertex-degree-based structure descriptors were the graph invariants that nowadays are called Zagreb indices. However, initially these were intended to be used for a completely different purpose (see below), and these were included among topological indices much later. The first genuine degree-based topological index was put forward in 1975 by Milan Randić in his seminal paper "On characterization of molecular branching”. His index was defined as

$$
\mathrm{R}(\mathrm{G})=\sum_{u v \in E(G)} \frac{1}{\sqrt{d u d v}}
$$

\section{Atom-bond Connectivity Index:}

Let $e$ be the edge of the molecular graph $G$, connecting the vertices $u$ and $v$. Then the term $d u d v$ in the definition of the Randic index. It is the product of degrees of the end-vertices of the edge $e$. The degree of this edge, i.e., the number of edges adjacent to $e$ is equal to $d u+d v-2$. In order to take also this information into account, Ernesto Estrada conceived a new topological index that is an amended he named it "atom-bond connectivity index" which is conveniently abbreviated by $A B C$. It is defined as

$$
\mathrm{ABC}(\mathrm{G})=\sum_{u v E(G)} \sqrt{\frac{d u+d v-2}{d u d v}}
$$


Augmented Zagreb Index:

Motivated by the success of the $A B C$ index, Furtula et al.put forward its modified version, that they somewhat inadequately named "augmented Zagreb index". It is defined as

$$
\mathrm{AZI}(\mathrm{G})=\sum_{u v \in E(G)}\left(\frac{d u d v}{d u+d v-2}\right)^{3}
$$

\section{Geometric-arithmetic Index:}

Another recently conceived vertex-degree-based topological index utilizes the difference between the geometric and arithmetic means, and is defined as

$$
\mathrm{GA}(\mathrm{G})=\sum_{u v \in E(G)} \frac{2 \sqrt{d u d v}}{d u+d v}
$$

Where, of course, $\sqrt{d u \cdot d v}$ and $\frac{d u+d v}{2}$ are the geometric and arithmetic means, respectively, of the degrees of the end-vertices of an edge. Recall that the former is always less than or equal to the later. The index was invented by Vukičević and Furtula and was named "geometric-arithmetic index".

\section{Harmonic Index:}

In the 1980s, Siemion Fajtlowicz created a computer program for automatic generation of conjectures in graph theory. Then he examined the possible relations between countless graph invariants, among which there was a vertex-degree-based quantity

$$
\mathrm{H}(\mathrm{G})=\sum_{u v \in E(G} \frac{2}{d u+d v}
$$

With a single exception $H(G)$ did not attract anybody's attention, especially not of chemists. Only in 2012, Zhang re-introduced this quantity, and called it "harmonic index". His works were followed by the recent paper. No chemical applications of the harmonic index were reported so far, but, knowing the present situation in mathematical chemistry, such researches are very much to be expected.

\section{Main Result And Discussion}

Molecular graphs for isomers of butane

Fig. (a)



Fig. (b)

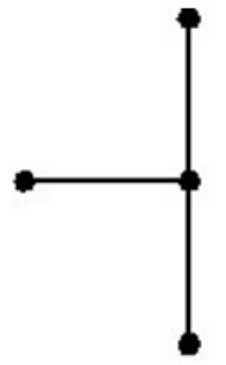

Fig. (c)

Adjacency Matrix

$$
\left[\begin{array}{llll}
0 & 1 & 0 & 0 \\
1 & 0 & 1 & 0 \\
0 & 1 & 0 & 1 \\
0 & 0 & 1 & 0
\end{array}\right]
$$

Fig. (a)

$$
\left[\begin{array}{llll}
0 & 1 & 0 & 0 \\
1 & 0 & 1 & 1 \\
0 & 1 & 0 & 0 \\
0 & 1 & 0 & 0
\end{array}\right]
$$

Fig. (b)

$$
\left[\begin{array}{llll}
0 & 1 & 0 & 0 \\
1 & 0 & 1 & 1 \\
0 & 1 & 0 & 0 \\
0 & 1 & 0 & 0
\end{array}\right]
$$

Fig. (c) 


\section{Calculation:}

\section{Fig (a):}

1) Randic index, $\mathrm{R}(\mathrm{G})=\sum_{u v \in E(G)} \frac{1}{\sqrt{d u d v}}$

$$
\begin{aligned}
R(G) & =\frac{1}{\sqrt{1 \times 2}}+\frac{1}{\sqrt{2 \times 2}}+\frac{1}{\sqrt{2 \times 1}} \\
& =1.9142
\end{aligned}
$$

2) Atom-bond connectivity index, $\operatorname{ABC}(\mathrm{G})=\sum_{u v \in E(G)} \sqrt{\frac{d u+d v-2}{d u d v}}$

$$
\mathrm{ABC}(\mathrm{G})=\sqrt{\frac{1+2-2}{1 \times 2}}+\sqrt{\frac{2+2-2}{2 \times 2}}+\sqrt{\frac{2+1-2}{2 \times 1}}
$$

$$
=2.12
$$

3) Augmented Zagreb index, AZI $(\mathrm{G})=\sum_{u v \in E(G)}\left(\frac{d u d v}{d u+d v-2}\right)^{3}$

$$
\begin{aligned}
\mathrm{AZI}(\mathrm{G}) & =\left(\frac{1 \times 2}{1+2-2}\right)^{3}+\left(\frac{2 \times 2}{2+2-2}\right)^{3}+\left(\frac{2 \times 1}{2+1-2}\right)^{3} \\
& =24
\end{aligned}
$$

4) Geometric-arithmetic index, GA $(\mathrm{G})=\sum_{u v \in E(G)} \frac{2 \sqrt{d u d v}}{d u+d v}$

$$
\begin{aligned}
\mathrm{GA}(\mathrm{G}) & =\frac{2 \sqrt{1 \times 2}}{1+2}+\frac{2 \sqrt{2 \times 2}}{2+2}+\frac{2 \sqrt{2 \times 1}}{2+1} \\
& =2.88
\end{aligned}
$$

5) Harmonic index, $\mathrm{H}(\mathrm{G})=\sum_{u v \in E(G} \frac{2}{d u+d v}$

$$
\begin{aligned}
H(G) & =\frac{2}{1+2}+\frac{2}{2+2}+\frac{2}{2+1} \\
& =2.33
\end{aligned}
$$

Table.1: The topological indices values of n-butane isomers.

\begin{tabular}{|l|l|l|l|l|l|}
\hline $\begin{array}{l}\text { Topological } \\
\text { structure }\end{array}$ & $\begin{array}{l}\text { Randic } \\
\text { Index }\end{array}$ & $\begin{array}{l}\text { ABC } \\
\text { Index }\end{array}$ & AZ Index & GA Index & $\begin{array}{l}\text { Harmonic } \\
\text { Index }\end{array}$ \\
\hline Fig.(a) & 1.92 & 2.12 & 24 & 2.88 & 2.33 \\
\hline Fig.(b) & 1.732 & 2.44 & 10.12 & 2.59 & 1.5 \\
\hline Fig.(c) & 1.732 & 2.44 & 10.12 & 2.59 & 1.5 \\
\hline
\end{tabular}

\section{Conclusion}

The topological indices are determined for isomers of Butane. AZ index has higher value for n-butane and it decreases with branching in the structure and the same case is followed for degree-based topological indices, $\mathrm{ABC}(\mathrm{G}), \mathrm{GAI}(\mathrm{G}), \mathrm{ABC}(\mathrm{G}), \mathrm{H}(\mathrm{G}))$.

\section{References}

[1]. K.C.Das, Atom-bond connectivity index of graphs, Discr.Appl.Math.158 (2010) 1181-1188.

[2]. K.C.Das, I.Gutman, B.Furtula, On atom-bond connectivity index, Chem.Phys.Lett.511 (2011)452-454

[3]. Estrada, Atom-bond connectivity and the energetic of branched alkanes, Chem.Phys.Lett.463 (2008) $422-425$.

[4]. B.Furtula, A.Graovac, D.Vukicevic, Atom-bond connectivity index of tree, Discrete Appl.Math.157 (2009)2828-2835.

[5]. K.C.Das, N.Trinajstic, Comparison between first geometric-arithmetic index and atom-bond connectivity index, Chem.Phys.Lett.497 (2010)149-151.

[6]. Trinajstic.N, Chemical Graph Theory, CRC Press, Boca Raton (1992). 
[7]. D.Vukicevic and B.Furtula, Topological index based on the ratios of geometrical and arithmetical mean of end-vertex degrees of edges, J.Math.Chem, 26, (2009)1369-1376.

[8]. Ivan Gutman, Degree-based topological indices, Croat.Chem.Acta, 86(4) (2013)251-361.

[9]. K.C.Das, Atom-bond connectivity index of graphs, Discr.Appl.Math.158 (2010) 1181-1188.

[10]. N.K.Raut, Degree Based Topological Indices of Isomers of Organic Compounds, International Journal of scientific and Research Publications, Volume 4, Issue 8, August 2014

[11]. Shigehalli.V.S, Rachanna.Kanabur, Correlation between the Arithmetic-Geometric Indices of n-heptane Alkane Isomers, IOSR Journal of Mathematics(IOSR-JM), 12(2), Ver.IV (2016),36-39.

[12]. Shigehalli.V.S, Rachanna.Kanabur, Degree Based Topological Indices Of n-Heptane Isomers, JAMAL ACADEMIC RESEARCH JOURNAL: An Interdisciplinary Special Issue (2016), 235-238. 